\title{
Blows and Voluntary Wounds of the Emergency Unite in Gabriel Toure Teaching Hospital in Bamako
}

\author{
Mangané Moustapha1, Diop Thierno Madane', Almeimoune Abdoul Hamidou', Keita Soumaila ${ }^{2}$, \\ Dembelé Aladji Seydou ${ }^{3}$, Youssouf Sogoba4, Konaté Madiassa5, Koita Siriman6, \\ Traoré Amadou', Issa Amadou7, Badimi Siaka1, Abdoulaye Kanté2, Diallo Sadio1, \\ Sangaré Harouna ${ }^{1}$, Dembelé Bakary Tientigui ${ }^{5}$, Togo Adegné5, Diango Djibo Mahamane ${ }^{1}$
}

\footnotetext{
${ }^{1}$ Department of Anesthesiology and ICU, Hôpital Gabriel Touré, Bamako, Mali

${ }^{2}$ Department of General Surgery, Hôpital du Point G, Bamako, Mali

${ }^{3}$ Department of Anesthesiology, Hôpital IOTA, Bamako, Mali

${ }^{4}$ Department of Neurosurgery, Hôpital Gabriel Touré, Bamako, Mali

${ }^{5}$ Department of General Surgery, Hôpital Gabriel Touré, Bamako, Mali

${ }^{6}$ Department of Anesthesiology and ICU, Hôpital Mère-Enfant, Bamako, Mali

${ }^{7}$ Department of Pediatric Surgery, Hôpital Gabriel Touré, Bamako, Mali

Email: mbayemangane@gmail.com
}

How to cite this paper: Moustapha, M. Madane, D.T., Hamidou, A.A., Soumaila, K., Seydou, D.A., Sogoba, Y., Madiassa, K., Siriman, K., Amadou, T., Amadou, I., Siaka, B., Kanté, A., Sadio, D., Harouna, S., TientiguiM D.B., Adegné, T. and Mahamane, D.D. (2018) Blows and Voluntary Wounds of the Emergency Unite in Gabriel Toure Teaching Hospital in Bamako. Surgical Science, 9, 334-343.

https://doi.org/10.4236/ss.2018.99040

Received: August 11, 2018

Accepted: September 25, 2018

Published: September 28, 2018

Copyright $\odot 2018$ by authors and Scientific Research Publishing Inc. This work is licensed under the Creative Commons Attribution International License (CC BY 4.0).

http://creativecommons.org/licenses/by/4.0/ Open Access

\begin{abstract}
Introduction: Voluntary assault and injuries are acts that damage the physical and psychological integrity of a human being. WHO in its global report on violence and health estimates that in 2000, 1.6 million people worldwide died as a result of self-harm, interpersonal or collective violence, resulting in an overall rate adjusted by age of 28.8 per 100,000 population. Because of the seriousness of this phenomenon and the heavy socio-economic and health consequences that they generate, it seemed important to us to undertake this study, which aimed to study the deliberate injuries in the emergency unite of the Gabriel Touré Teaching Hospital in Bamako. Material and methods: This was a descriptive and cross-sectional study with a prospective study from September 1st, 2016 to August 31st, 12 months, covering 295 patients, including any patient received for voluntary injury consultation with a workable medical record and/or a full investigation record with or without requisition. Our data were collected on individual survey cards and subsequently analyzed with Word, Excel, IBM SPSS Statistics 22 software. Results: The majority of victims of assault and bodily injury were male with $83.1 \%$; with a sex ratio of 4.9 , the 18 to 28 age group was the most concerned with 163 cases of the 295 cases in our study, 55.2\%. The extremes were 6 and 100 years old with an ectype at 11.08 . The most affected ethnic group was Bambara with
\end{abstract}


$38.6 \%(n=114)$ followed by Fulani with $15.6 \%(n=46)$. Students were the most affected at $24.7 \%(\mathrm{n}=73)$, followed by traders at $10 \%$. The victims coming from outside Bamako are the most predominant with $22.4 \%(n=66)$ followed by those of commune IV of Bamako $15.6 \%(n=46)$. In $92.2 \%$ of the cases the mechanism was direct with $n=272$. Of the lesions recorded in our study, wounds came first with $53.2 \%$ of cases. Radiography was the most used imaging at $44.7 \%(n=89)$ followed by computed tomography at $34.7 \%(n=$ 69). The hemoperitoneum objectified by abdominal ultrasound represented 29.3\% ( $n=12)$. Fractures embarrure associated with bruising-hemorrhagic bruises were the most predominant with $13.4 \%(n=10)$ objectified by brain scan. Conclusion: We note that the phenomenon of violence has reached worrying proportions, especially among young adults, particularly among students and is observed in all socio-professional layers. The polymorphism of these injuries caused by the predominant use of knives must draw the attention of our authorities to take measures to reduce these aggressions.

\section{Keywords}

Blows, Wounds, EU, Gabriel Touré University Hospital

\section{Introduction}

The voluntary aggravated assault aims at the acts which undermine the physical and psychological integrity of a human being. They are known as volunteers when their author had the will to make a violent act, responsible for all the traumatic consequences, including those which it did not wish CEs traumatisms represent a real problem of public health in the countries little secured by Africa where they are associated many factors such as poverty, unsuited town planning, the lack of the qualified and justified labour [1]. It is a rapid movement at the end of which a body comes to strike another body [2]. Injury is an accidental or deliberate injury to a living organism following a stroke, shock, burn, using a weapon, a sharp or blunt instrument [3]. WHO in its Global Report on Violence and Health estimates that in 2000, 1.6 million people worldwide died from self-harm interpersonal or collective, giving an overall age-adjusted rate of 28.8 per 100,000 population [4]. WHO in 2001 estimated that 1 million people were intentionally killed each year worldwide [5]. They constitute the second cause of admission after the accidents of the public highway to the service of the surgical urgencies of the hospital Gabriel Touré according to Kanikomo D et al. [6]. Because of gravity of this phenomenon and heavy socio-economic and medical consequences that they generate, it appeared significant to us to undertake this study on the CBV with the SAU. The objective was to study the CBV in the service of reception of the urgencies of the CHU Gabriel Touré of Bamako.

\section{Material and Methods}

It was about a study descriptive, transverse and prospective energy of September 
1, 2016 with the 31 Août 2017 is 12 months. Our study took place in the Hospital Emergency Department of Gabriel Touré University Hospital covering 295 patients. We included any patient of any age and sex received in consultation for traumatisms by voluntary aggravated assault having an exploitable medical file and or a card of complete investigation with or without requisition. The emergency reception service receives an average of 20,000 patients a year and welcomes all emergencies except medico-pediatric and obstetric emergencies. With the admission, each victim of aggravated assault volunteer profited from a complete clinical examination. With the exit of which of the need a complementary examination was required and reported on a medical file and or a card of individual investigation into which were mentioned the variables of identifications (name, first name, age, sex, profession, residence), the clinical variables, circumstances of occurred, mechanism, the etiology, the types of lesions, the quality of the expert, the date and the hour of the examination, the commemorative ones, the complaints of the victim, the medico-surgical antecedents likely to interfere with the consequences of undergone violences or to inform about a state of vulnerability the examinations paraclinic, the diagnosis, the treatment and the evolution. Our data were collected on cards of investigation individual and analyzed thereafter with software Word, Excel, IBM SPSS Statistics 22. On the ethical level, the informed consent of the patents was approached after a careful explanation of the type of study.

\section{Results}

During our period of study we recorded 295 victims of voluntary aggravated assault. The men were more victims of the CBV in $83.1 \%$ with a sex-ratio $=4.9$. The age bracket from 18 to 28 years was most concerned with 163 cases out of the 295 cases of our study, that is to say 55.2. The extremes were 6 and 100 years with an ectype with 11.08 . The ethnos group bambara will epresent with $38.6 \%$ $(\mathrm{n}=114)$ followed peuls $15.6 \%(\mathrm{n}=46)$. The pupils and the students were touched the $24.7 \%(\mathrm{n}=73)$, followed tradesmen $10 \%$. We recorded more patients coming out of the town of Bamako 22, $4 \%(\mathrm{n}=66)$, then commune VI = $15.6 \%(n=46)$. The arguments with unknown were the circumstances most prevalent 30.5\% $(n=90)$ (Table 1). Followed steerings $23.4 \%(n=69)$. The month most concerned was that of February $14.6 \%(n=43)$, apart from this month it $y^{\prime}$ had a constant number of victim of CBV. The mechanism was direct in $92.2 \%$ of the cases $(\mathrm{n}=272)$. The most accused agents were the bayonets $51.2 \%(\mathrm{n}=151)($ Table 2$)$. Of the recorded injuries the wounds were the most frequent $53.2 \%$ of the cases. We observed a prevalence of the lesions on the level of the head with 100 cases is $33.9 \%$ (Table 3 ). The traumatized cranial ones were the diagnosis majority with $27.5 \%(\mathrm{n}=81)$. The radiography was the imagery most used with $44.7 \%(n=89)$ followed tomodensitometry with $34.7 \%(n=69)$. The hémoperitoine objectified by abdominal echography accounted for $29.3 \%$ (n = 12). The TDM found fractures embarrures associated with oedémato-hemorrhagic contusions in $13.4 \%(\mathrm{n}=10)$ and the hémothorax $20.7 \%(\mathrm{n}=$ 
Table 1. The circumstance of which has occurred.

\begin{tabular}{ccc}
\hline Circumstance & Manpower & Percentage \\
\hline Dispute with unknown & 90 & 30.5 \\
Steering & 69 & 23.4 \\
Dispute between friend & 39 & 13.2 \\
Brawls & 23 & 7.8 \\
Popular verdict & 19 & 6.4 \\
Family conflict & 18 & 6.1 \\
Marital conflict & 12 & 4.1 \\
Not specified & 2 & 0.7 \\
Other & 23 & 7.8 \\
Total & 295 & 100 \\
\hline
\end{tabular}

Table 2. Etiology.

\begin{tabular}{ccc}
\hline Etiology & Manpower & Percentage \\
\hline Bayonet & 151 & 51.2 \\
Arm with fire & 59 & 20 \\
Blunt object & 29 & 9.8 \\
Blow of fist & 8 & 2.7 \\
Not specified & 8 & 2.7 \\
Kick & 2 & 0.7 \\
Other & 38 & 12.9 \\
Total & 295 & 100 \\
\hline
\end{tabular}

Table 3. The seat of the lesion.

\begin{tabular}{ccc}
\hline Sit of the lesion & Manpower & Percentage \\
\hline Head & 100 & 33.9 \\
Abdomen & 50 & 17 \\
Former thorax & 32 & 10.8 \\
Lower limb & 29 & 9.8 \\
Upper limb & 24 & 8.1 \\
Posterior thorax & 4 & 1.4 \\
Neck & 2 & 0.7 \\
Other & 54 & 18.3 \\
Total & 295 & 100 \\
\hline
\end{tabular}

11). The recorded deaths (5.4\%) were especially associated the lesions caused by the bayonets in $50 \%$ of the cases $(n=8)$ (Figure 1$)$ and the polytraumatism in $37.5 \%$ (Figure 2). The evolution was favorable in $57 \%$ of the cases.

The arguments with unknown were the most predominant circumstances 


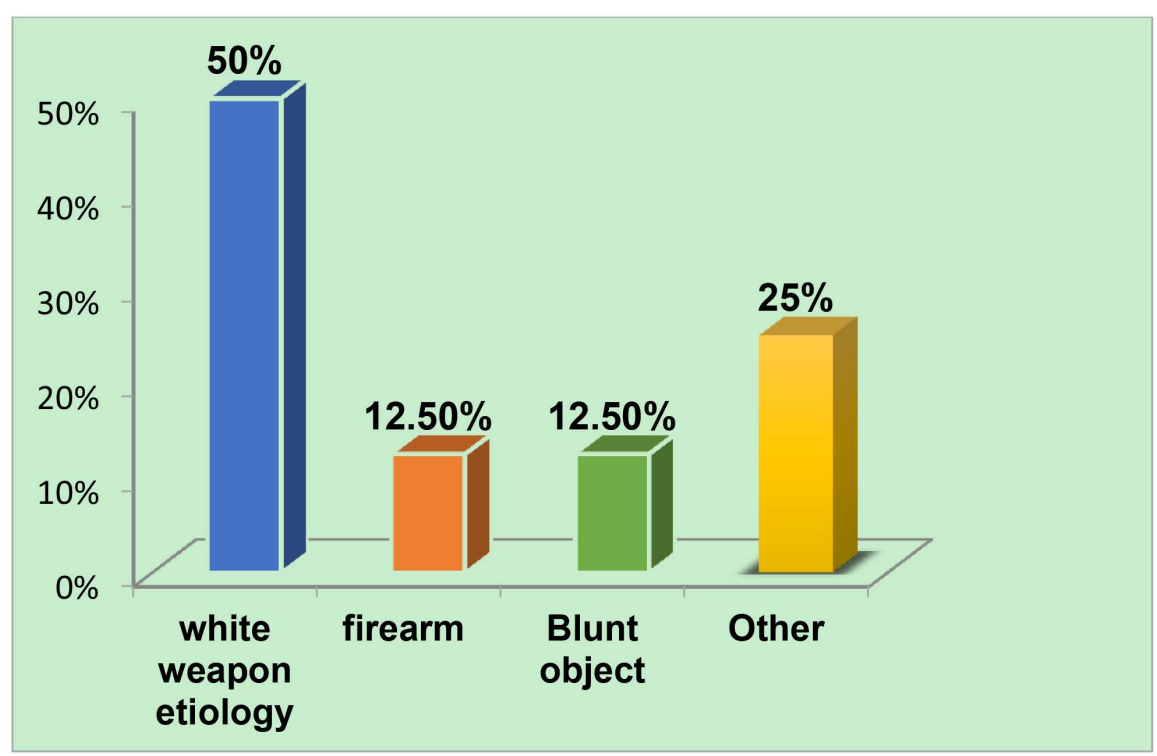

Figure 1 . Breakdown by diagnosis and death rate. The recorded deaths were mostly related to stab wounds with $50 \%$ of cases $(n=8)$.

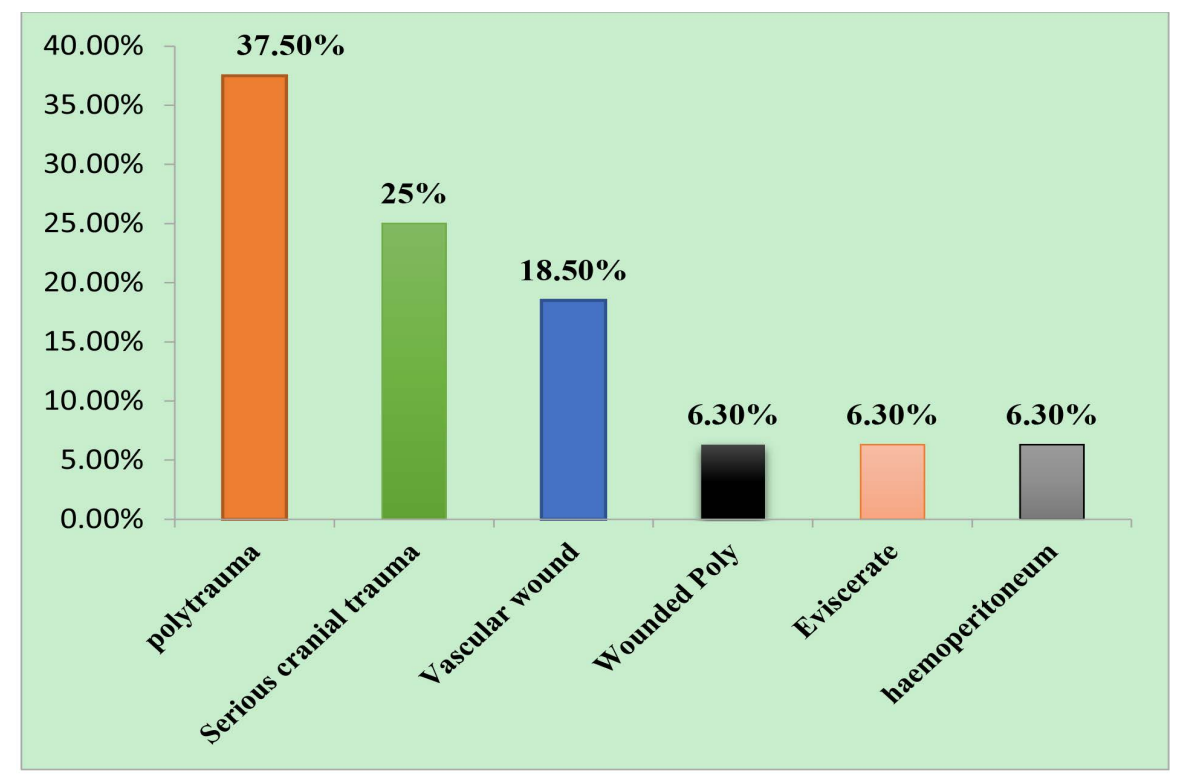

Figure 2. Distribution of patients by diagnosis and death. $37.5 \%$ of deaths were caused by polytrauma.

with $30.5 \%(n=90)$ followed by robberies with $23.4 \%(n=69)$.

The most incriminated agents were knives with $51.2 \%(n=151)$.

NB: The 38 others were victims of aggression by many types of weapons.

We observed a predominance of lesions in the head with 100 cases or $33.9 \%$.

Noting well: The other 54 cases are patients who had multiple injury seats.

\section{Comments and Discussion}

This work was an exploratory study over twelve months of the epidemiologic 
aspects; clinical of the voluntary aggravated assault we recorded 295 victims of voluntary aggravated assault. These figures are far from being exhaustive taking into account the fact that the CHU Gabriel Touré does not receive all the cases of admission for aggravated assault. We did not take account of the aspects médicolégaux and psychological catch of load in the study in the sense that the CHU Gabriel Touré does not lay out of psychiatric service even less one psychologist and the aspect médicolégal (of the total disablement of work (ITT) was dealt with by neurosurgeon legist after transfer of the victim of the urgencies towards the unit of neurosurgery. It during the following observations can be done in particular the male sex was prevalent with $83.1 \%$ is a sex/ratio with 4.9 same observation made by Mr. Dikesa, et al. [7] in its study on violence on the places of work. An Australienne study carried out by Rebecca J Mitchell [8] bearing on the intentional wounds inflicted to the children of less than 16 years shows a high proportion of hospitalization of female sex for the age bracket of 11 - 16 years. On the other hand Lançon V et al. [9] answer the result of our series by the prevalent proportion of the men victims of urban violences contrary to the women mainly domestic victims of violences. The high rate of the male sex in our study would be explained by the fact that the men are more prone to cause or to defend themselves at the time of the brawls, therefore often suffer body injuries. This percentage of men victims of CBV does not mean that it $\mathrm{y}^{\prime}$ has more men attacked in the population in general. The majority of our patients exposed to the voluntary aggravated assault was the young people, the most touched age bracket was that from 18 to 28 years, a frequency of $55.2 \%$ and one 23 years median age. This frequency is superposable with those found in other studies Ojo E et al. [10], Iram Khan Al [11], or it age bracket the most touched was that from 21 to 40 years, with a frequency of $75 \%$ and $65 \%$. This rate could be explained by the fact why the young people are in the mediums of many brawls; what exposes them to the risks of voluntary aggravated assault. The pupils and the students were represented in our series with $24.7 \%$. Ojo E et al. [10], find a prevalence of the stockbreeders and the farmers accused in their series. Iram Khan $\mathrm{Al}[11]$, in his series, the attacker was not known victim in the majority of the cases with $47,86 \%$. This could be explained by the fact why the great majority of our population consists of these two most fragile layers and by the growth of violences in educational circle. The victims of CBV came primarily except Bamako with 22.4\%. In the district of Bamako those are coming them from communes IV, V and II That would be explained on the one hand by a strong density of these districts, unemployment, constructions anarchistic and on the other hand owing to the fact that these districts are offset enough compared to the city in fact of the refuges for the delinquents. The arguments with unknown mainly at the time of the brawls during regroupings (estudiantins, sporting), at the market, of the political meetings or other reunion causing of the arguments were in our series the most prevalent circumstances with $30.5 \%$ follow-up of the steerings with $23.4 \%$. The bayonets and the weapons with fire were 
used with 51.2\% and 20\%. According to Bège T et al. [12] in France, the wounds by bayonets represent the most frequent cause of penetrating wounds and occur mainly with the waning of an aggression, superposable with the observations made by MonsefBl et al. [13] with the CHU fold back in Morocco on 245 cas aggressions recruited over one period of 3 mois during which the bayonets were used at the time of the aggressions by delinquents or during brawls. Ojo E et al. and Iram Khan et al. [10] [11] find a high proportion of intentional wounds per weapon with fire à. $70 \%$ and $80 \%$ in their series. The use of the bayonet in the majority of the cases would be explained by its weak cost and its accessibility for all the age brackets. There is not a control of the gun licencewhite. On the other hand, the automatic weapons with fire cost expensive and their acquisition is not always easy. That encourages us to reflect on the great accessibility of the weapons with fire called to "artisanal manufacture" and the relaxation of the rigour in the legislation on the weapons to fire. In our series we found a prevalence of the lesions on the level of the head with $33.9 \%$. Our study joined the majority of series Apnet, Samu, Bouchra Bouyousfi, et al. [14] [15] which confirm the prevalence of the lesions interest mainly the head, the upper limb, and the lower limb. Contrary to Vion B et al. and Bouchra Bouyousfi [15] [16] in their series which notes the prevalence of the lesions on the level of the upper limb who could be explained on the one hand, by the fact that the upper limb is often aimed by the attacker (flights of jewels, telephones portable... etc.) and in addition, by the fact that it is often used as means of defense for the victim. In our context the head is much more easily accessible to the agents traumatisants (bayonets, blunt objects, blow of fist). The nature of the lesions was variable, the cutaneous wounds come to the first rank from the lesions recorded at the time of the CBV where they accounted for $53.2 \%$ in our study. Even report made by Mohamed Mr. [17] which notes a prevalence of the wounds (36.4\% of the cases). Other studies relating to the evaluation of the quality of drafting of descriptive certificates of observations of voluntary aggravated assault led in France and to Morocco [18] [19] [20] found the prevalence of other lesions. They are the hématomes and bruises (51\%) for the study undertaken by Benyaich and collar within the medico-legal unit the CHU IbnRochd Casablanca [18]. The wounds occupied the second place (35\% of the cases). For the study undertaken by Grill and coll. within the médico-legal unit of the CHU of Rangueil of Toulouse, the bruises were dominating (782 cases), the wounds came only in 4th position (201 cases) respectively after the dermabrasions and burns (759 cases) and the hématomes (295 cases) [19]. Finally as regards the study undertaken by Louarn and collar [20], one noted a prevalence of the hématomes and bruises. On the other hand the complex lesions remain most frequent in the series of POTARD [21], which could be explained partly by the anatomical complexity of the upper limb as well as the proximity of the anatomical elements being able to generate not only simple lesions but also of the lesions of vicinity. The emotional state and the behavior of the victim observed during the medical examination were men- 
tioned little in our series. This joined the study undertaken by Louarn and coll. [20] which stresses that it is recommended to the doctor to describe the psychic signs noted with the medical examination. If the medical examination does not have as an aim to pose a psychological diagnosis, the doctor can note the behavior of the victim and/or its emotions (evaluation of the psychological state) because in fact elements will testify to the existence of a secondary state of shock to the aggression (traumatic state of shock post or traumatic state of stress post). This state can be variable, energy of the simplest demonstrations (fear, distresses...) to disorders much more serious (psychosis, depression...). Announce in addition that these behavioral problems can as be invalidating for the victim from the physiological and functional point of view as the physical lesions. Standard radiography was the examination more used in our series with $44.7 \%$ follow-up of the tomodensitometry with $34.7 \%$. The hémoperitoine accounted for $29.3 \%$ out of 41 echography carried out. This rate would be explained by the fact of the surface of the abdomen and by its anatomical situation makes it available to the traumatic agents (bayonets and weapons with fire). In our series the fractures embarrures associated with oedémato-hemorrhagic contusions were majority with $13.4 \%$ out of 69 tomodensitométries carried out. In our study the hémothorax represented a prevalence with $20.7 \%$ out of 51 tomodensitométries carried out. The buckshots in the members were in a majority with $20.2 \%$ out of 89 radiographies carried out. The medical treatment was in a majority with a rate of $53.2 \%$ of the cases. This rate is explained by made that the majority of the lesions were less serious lesions. Monsef B et al. [13] brought back $100 \%$ of the medical processing in their series. With opposite OJO E et al. [10] observed a prevalence of the surgical type treatment of laparotomies, amputations and the installation of external fixer for the open fractures of the long bones. It comes out from our study that the evolution of the lesions resulting from the aggravated assault is in general favorable with $57 \%$. We recorded 16 case of death i.e. $5.4 \%$. The cases of death were caused primarily by the polytraumatism and the cranial traumatism with 37.5\% either 6 deaths of the cases and $25 \%$ or 4 deaths of the cases. Our results are comparable with those of Ojo E et al. [10] which observed a mortality of $3.36 \%$ the duration of hospitalization was estimated on average 5 jours in our study. Monsef B et al. [13] found one duration average of hospitalization of 3 jours on the other hand Ojo E et al. [6] brings back one average duration of 30 jour in its series which could be explained by the high frequency of the more complex lesions.

\section{Conclusion}

The phenomenon of violence took worrying proportions especially in the young adults in particular in the pupils and students, and was observed in all the socio-professional layers. The polymorphism of these lesions caused by the bayonets with prevalence must draw the attention our authorities to undertake measurements to decrease these aggressions. 


\section{Conflicts of Interest}

The authors declare no conflicts of interest regarding the publication of this paper.

\section{References}

[1] Odimba, E. (2007) Particular Aspects of the Traumatisms in the Countries Little Secured by Africa. One Lived Surgical 20 Years. Emémoires of the National Academy of Surgery, 6, 44-56.

[2] Sur Centre National de Ressources Textuelles et Lexicales. http://www.cnrtl.fr/definition/coups

[3] Sur Centre National de Ressources Textuelles et Lexicales. http://www.cnrtl.fr/definition/blessure

[4] World Heath Organization Sur Rapport mondial sur la violence et la santé sur. http://www.who.int/violence_injury_prevention/violence/world_report/fr/

[5] Sand, E.A., Jeanneret, O. and Romer, C. (1996) Violence and Aggression in Adolescents Andyoung Adults. Review of the Recent Literature. Revue d'Epidémiologie et de Santé Publique, 44, 301-345.

[6] Kanikomo, D., Sogoba, Y., Rammed, M., Coulibaly, O. and Diarra, MS. (2015) Epidemiologic, Clinical and Therapeutic Study of the Fractures Embarrures of Cranium in Connection with 72 Cases in the Service of Neurosurgery of the CHU Gabriel Toure of Bamako. Medical Mali, 30, 7-12.

[7] Dikes, M. and Fraga, S. (2012) Les coups et blessures volontaires sur les lieux du travail. Archives des Maladies Professionnelles et de I Environnement, 73, 573. https://doi.org/10.1016/j.admp.2012.03.665

[8] Mitchell, R.J., Seah, R., Ting, H.P., Curtis, K. and Foster, K. (2018) Intentional Coil-Harm and Assault Hospitalizations and Treatment Cost of Children in Australia over Has 10-Year Period. Australian and New Zealand Newspaper of Public Health, 42, 240-246.

[9] Lançon, V. and Moiron, L. (2009) Victims of Aggressions: Profiles of Consultation and Limits of the Current Methods of Assumption of Responsibility in a Service of Reception of the Urgencies. Journal Européen des Urgences, 22, A112-A113. https://doi.org/10.1016/j.jeur.2009.03.397

[10] Ojo, E., Ibrahim, A., Alabi, S. and Obiano, S. (2007) Gunshot Insult in a North Eastern Nigerian Tertiary Hospital. The Internet Newspaper of Surgery, 16, 1-8.

[11] Khan, I., Shakeel, M., Usmani, J.A. and Hasan. S.A. (2016) Emerging Trends of Intentional Firearm Insult in Northern India: A Study. Journal of Clinical and Diagnostic Research, 10, Hc01-Hc04.

[12] Bège, T., Berdah, S.V. and Brunet, C. (2013) Les plaies par arme blanche et leur prise en charge aux urgences. La Presse Médicale, 42, 1572-1578.

[13] Boufettal, M., Mahfoud, M., Ismael, F., Kharmaz, M., El Bardouni, A., Berrada, M.S. and El Yaacoubi, M. (2015) Moradh EiPlaies des membres par agression: Analyse de 245 dossiers. Pan African Medical Journal, 22, 183.

[14] Carli, P., et al. (2005) Dealt with of the Wounds to the Urgencies. 12 th Conference of Consensus, December 2005, 1-43

[15] Bouyousfi, B. (2001) Violence in Traumatology in the Town of Marrakech. Thesis of General Medicine, Université Cadi Ayyad of Facult of Pharmacie, 80. 
[16] Vion, B., et al. (2010) Dealt with of the Wounds to the Urgencies Study of Practice to the CHU of Angers. Newspaper European of the Urgencies, 23, 59-64. https://doi.org/10.1016/j.jeur.2010.06.002

[17] Mohamed, M., Hugues, E.E., Mor, N. and Mamadou, R. (2011) Sow Quality of the Certificates of Voluntary Aggravated Assault on Adults in Dakar and Diourbel, Senegal. South African Medical Journal, 10, 59.

[18] Benyaich, H., Razik, H., Chbani, A., El Khalil, M. and Louahlia, S. (2004) Consultation of the Victims of Voluntary Aggravated Assault with the CHU IbnRoch of Casablanca: Transverse Victimologic Study of 400 Files. Journal de Medecine Legale Droit Medical, 47, 193-199.

[19] Grill, S., White, A., Dedouit, F., Red, D. and Telmon, N. (2006) Evaluation of the Quality of the Drafting of the Descriptive Certificates of the Observations of Voluntary Aggravated Assault within a Médico-Legal Unit. Journal de Medecine Legale Droit Medical, 49, 166-172.

[20] Louarn, A., Schweitzer, B. and Reitzer, C. (2005) Rédaction of a Medical Certificate in the Event of Maltraitance in the Child: Evaluation of the Practices of the Doctors of National Education. Journal de Medecine Legale Droit Medical, 48, 469-477.

[21] Potard, D. and Petit, G. (1992) La consultation des victimes de coups et blessures volontaires de l'Hôtel-Dieu de Clermont-Ferrand: Bilan d'activité 1986-1990. Société de médecine légale 11. 